\title{
Enhancing a primary care environment: a case study of effects on patients and staff in a single general practice
}

Gillian Rice, Jenny Ingram and Jacques Mizan

\section{ABSTRACT}

\section{Background}

Few studies have examined the effect on patients and staff of the physical environment in primary care facilities. Aim

To explore changes in patient and staff satisfaction, patient anxiety, and patient-doctor communication when a GP surgery moves from old premises to enhanced purpose-built accommodation.

\section{Design of study}

Questionnaire surveys, interviews, and focus groups preand post move.

\section{Setting}

An urban general practice in Bristol.

\section{Method}

Patient questionnaires assessed anxiety (Spielberger State-Trait Anxiety Inventory; STAI), satisfaction with the environment, and communication during the

consultation. Staff questionnaires assessed satisfaction with the environment and job satisfaction. Qualitative methods explored patient and staff views in more depth.

Results

A total of 1118 pre-move and 954 post-move patient questionnaires showed significant increases in satisfaction scores for reception/waiting areas (mean $6.46,95 \%$ confidence interval $[\mathrm{Cl}]=5.97$ to 6.95 ) and consulting rooms (mean $3.80,95 \% \mathrm{Cl}=3.44$ to 4.15 ) in the new premises. Patients' satisfaction with patient-doctor communication also increased (mean $0.88,95 \% \mathrm{Cl}=0.30$ to 1.46 ) and anxiety scores were significantly reduced before and after the consultation in the new premises compared with the old (STAI mean difference before consultation $0.72,95 \% \mathrm{Cl}=0.37$ to 1.08; mean after consultation $0.37,95 \% \mathrm{Cl}=0.03$ to 0.72 ). Patients highlighted the increased space and light, more modern appearance, greater comfort, and novel works of art in the new surgery. Staff workplace satisfaction increased significantly after moving and remained higher than in the old building.

\section{Conclusion}

This large-scale study examining the effects of a UK primary care environment on patients and staff shows that an enhanced environment is associated with improvements in patients' perception of patient-doctor communication, reduction in anxiety, and increases in patient and staff satisfaction.

\section{Keywords}

environment design; health facility environment; job satisfaction; patient satisfaction; physician-patient relations; primary health care.

\section{INTRODUCTION}

Research has shown that the built environment (the physical design and décor in which health care is delivered) can exert significant effects on patients and staff. Ulrich and Zimring found more than 600 rigorous studies that show how the design of healthcare facilities can increase patient safety, remove patient stress, improve medical outcomes, reduce staff stress and fatigue, and improve overall healthcare quality. ${ }^{1}$

Most research into the links between healthcare environments and health outcomes has studied patients and staff in hospitals; very few studies have been carried out in a primary care setting. ${ }^{2-4}$ Eighty per cent of health care is delivered in such environments, yet little is known about the design of these spaces. Research presented by Ulrich and Zimring suggests that optimal design, whatever that might be, could result in a better patient and staff experience and more effective delivery of community health care. ${ }^{1}$ The present study begins to address this knowledge gap.

An opportunity arose to collect comparable sets of data at two linked sites when a general practice with

G Rice, M Phil, MRCP, MRCGP, GP, Bedminster Family Practice, Bristol. J Ingram, $B S c$, $P h D$, primary care research facilitator, Bristol Research and Development Support Unit, Bristol Royal Infirmary, Bristol. J Mizan, MSc, MRCGP, honorary research fellow, Department of General Practice and Primary Care, Kings College London, London.

\section{Address for correspondence}

Dr Gillian Rice, Bedminster Family Practice,

Regent Road, Bristol, BS3 4AT.

E-mail: Gillian.Rice@gp-L81082.nhs.uk

Submitted: 31 October 2007; Editor's response: 4 January 2008; final acceptance: 26 March 2008.

(C) British Journal of General Practice

This is the full-length article of an abridged version published in print. Cite this article as: Br J Gen Pract 2008; DOI: 10.3399/bjgp08X319422 
9200 patients moved from a converted Victorian house to new purpose-built premises.

The original building was cramped, with insufficient consulting and treatment rooms for all the health professionals working at the practice. The reception area was noisy and lacked privacy for patients in their dealings with receptionists, and the waiting areas were small, with only basic standards of comfort and decoration. The new surgery was designed with careful attention to lighting, noise, and furnishings. Overall, it was more spacious and consulting rooms were larger: up to $22 \mathrm{~m}^{2}$ compared with a maximum of $14.8 \mathrm{~m}^{2}$ in the old building. One GP working with an art consultant obtained grants from seven bodies (including Arts Council England, Awards for All, and the Quartet Community Foundation in Bristol) to commission art works that formed an integral part of the new surgery.

\section{METHOD}

This study compared the effect of two GP surgery environments on patients and staff to determine whether enhancing a primary care environment can alter patient anxiety while in the surgery, patient satisfaction, patient-doctor communication, staff wellbeing, and staff job satisfaction. It also aimed to identify specific elements of the surgery environment that might influence these variables.

Questionnaires, focus groups, and interviews were used to evaluate the effects of the environment on patients and staff before (phase 1) and after (phase 2) the move to new premises, which took place in November 2005. Staff questionnaires and focus groups were facilitated by a senior researcher to maintain anonymity of the data.

\section{Patient questionnaires and interviews}

Receptionists offered a two-part questionnaire to all patients attending the surgery for a GP appointment between April and September 2005 in the old premises, and between May and November 2006 in the new premises. The first part was completed while the patient sat in the waiting area, and the second part immediately after their consultation. The customised questionnaire explored:

- patient anxiety using the validated 6-item shortform of the Spielberger State-Trait Anxiety Inventory (STAI), ${ }^{5}$ before and immediately after their consultation with a GP;

- patient satisfaction with various aspects of the old surgery building and the new premises;

- doctor-patient communication using statements about patients' perception of how well the doctor listened, understood their problems, and relieved their worries (modified from Mizan and Ballard); ${ }^{2}$

\section{How this fits in}

Both patients and staff are affected by the physical environment in which health

care is delivered, but very few studies have been carried out in primary care

settings. This study suggests that enhancing a primary care environment is

associated with an improvement in patients' perception of patient-doctor

communication, reduced patient anxiety in the surgery, and increases in patient

and staff satisfaction.

eight statements (six positive and two negative) were selected.

Phase 1 and phase 2 participants were unmatched. Expected differences in STAI scores were used to calculate the sample size required, ${ }^{6}$ and it was estimated that 800 patients in each group would be sufficient to detect any differences in scores $(80 \%$ power to detect a difference in means of 1.33 between phase 1 and phase 2 patients using the 20 -item form of the STAI). ${ }^{6}$ From previous experience it was expected that approximately $60 \%$ of STAI questions would be completed, and that it would be necessary to distribute approximately 1300 questionnaires to achieve this.

Patients for interview were selected by purposive sampling to achieve a mix of age and sex, and invited to participate in semi-structured interviews held immediately after their consultation. The interviews explored patients' views on the environment in both settings.

\section{Staff questionnaires and focus groups}

All members of reception, administration, and managerial staff, and all permanent doctors and

Picture 1. New surgery exterior.

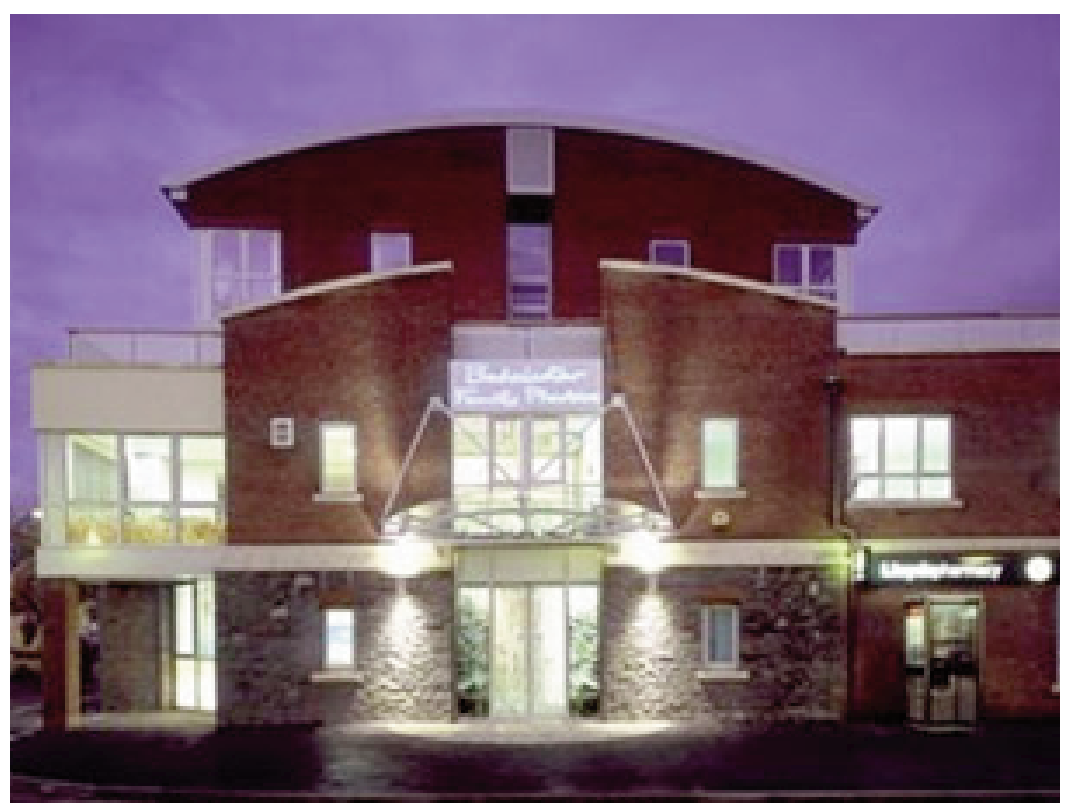


Table 1. Patient demographics.

\begin{tabular}{lcc} 
Demographic & $\begin{array}{c}\text { Phase 1 (\%) } \\
(n=1118)\end{array}$ & $\begin{array}{c}\text { Phase 2 (\%) } \\
(n=954)\end{array}$ \\
\hline Male & $372^{\mathrm{a}}$ & $316^{\mathrm{b}}$ \\
& $(35.1)$ & $(34.6)$ \\
\hline Female & $688^{\mathrm{a}}$ & $597^{\mathrm{b}}$ \\
& $(64.9)$ & $(65.4)$ \\
\hline Mean age, years & 48.8 & 47.8 \\
\hline Age range, years & $10-94$ & $13-90$ \\
\hline Consultation with & 617 & 585 \\
male doctor & $(55.2)$ & $(61.3)$ \\
\hline Consultation with & 501 & 369 \\
female doctor & $(44.8)$ & $(38.7)$ \\
\hline
\end{tabular}

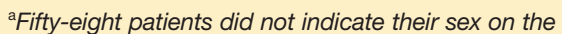
questionnaire. ${ }^{\mathrm{b}}$ Forty-one patients did not indicate their sex on the questionnaire.

nurses working at the surgery were asked to fill out the staff questionnaire, once before the move and on two occasions after it. Their questionnaire explored:

- satisfaction with various aspects of the current building, including their work areas and public parts of the surgery;

- job satisfaction; and

- psychological symptoms using the validated 12-item General Health Questionnaire (GHQ-12).

Volunteers attended three focus groups, held soon after questionnaires had been distributed, to explore staff views in more detail.

\section{Data management and analysis}

Total STAI scores were computed by reversing the scores for the three positive adjectives (calm,

\section{Table 2. Patient anxiety scores and satisfaction with the environment and doctor-patient communication in the old and new premises (unpaired $t$-tests).}

\begin{tabular}{|c|c|c|c|c|c|}
\hline & \multicolumn{2}{|c|}{ Score (patient numbers) } & \multirow[b]{2}{*}{$\begin{array}{c}\text { Mean } \\
\text { difference }\end{array}$} & \multirow[b]{2}{*}{$95 \% \mathrm{Cl}$} & \multirow[b]{2}{*}{$P$-value } \\
\hline & $\begin{array}{l}\text { Old premises } \\
\text { (phase 1) }\end{array}$ & $\begin{array}{l}\text { New premises } \\
\text { (phase 2) }\end{array}$ & & & \\
\hline $\begin{array}{l}\text { STAl before consultation } \\
\text { (range 6-24) }\end{array}$ & $11.65(975)$ & $10.93(845)$ & 0.72 & 0.37 to 1.08 & $<0.001$ \\
\hline $\begin{array}{l}\text { STAl after consultation } \\
\text { (range 6-24) }\end{array}$ & $10.50(935)$ & $10.12(800)$ & 0.37 & 0.03 to 0.72 & 0.033 \\
\hline $\begin{array}{l}\text { Reception/waiting } \\
\text { area satisfaction } \\
\text { (range 9-45) }\end{array}$ & 33.31 (960) & $39.77(775)$ & 6.46 & 5.97 to 6.95 & $<0.001$ \\
\hline $\begin{array}{l}\text { Consultation room } \\
\text { satisfaction } \\
\text { (range 6-30) }\end{array}$ & $22.95(1010)$ & $26.74(850)$ & 3.80 & 3.44 to 4.15 & $<0.001$ \\
\hline $\begin{array}{l}\text { Doctor satisfaction } \\
\text { (six doctors) } \\
\text { (range 6-42) }\end{array}$ & $37.61(715)$ & $38.49(590)$ & 0.88 & 0.30 to 1.46 & 0.003 \\
\hline
\end{tabular}

relaxed, content) and adding them to the negative adjectives (tense, upset, worried).

Patient satisfaction scores derived from 5-point Likert scales were computed from the questionnaires for the reception/waiting area and consultation room. Similarly, staff satisfaction scores with their workplace environment were computed. Initial factor analysis investigated whether summing item scores was adequate to produce these composite scores.

A patient 'doctor satisfaction' score was created using the six positive statements from Mizan and Ballard, ${ }^{2}$ since there was a statistically significant linear-by-linear association for each of the six items and when they were summed. The two negative items were not used as they showed no linear association. These statements used 7-point Likert scales.

\section{Analysis}

From the patient questionnaires, mean scores for STAI results, satisfaction with the reception/waiting area and consultation rooms, and 'doctor satisfaction' were compared between phases 1 and 2 using unpaired $t$-tests. Frequencies of coded freetext comments were compiled, and the most frequently reported topics described. From the staff questionnaires, comparisons were made using ANOVA to compare trends across all three questionnaire time points for staff who completed questionnaires in all phases.

Qualitative interviews and focus group transcripts were coded and subjected to thematic analysis using principles of constant comparison.

\section{RESULTS}

\section{Patient questionnaires}

In phase 1, 1400 questionnaires were given to patients and 1118 completed (79.9\%). In the new premises, 1200 questionnaires were handed out and 954 returned (79.5\%). Patient demographic characteristics are shown in Table 1.

Table 2 shows that STAI scores were reduced before and after the consultation in the new building compared with the old, possibly reflecting the calming influence of the new premises. Overall satisfaction scores for the reception/waiting area and consulting rooms were notably higher in the new premises. Scores for individual items (such as comfort of seating, noise level, and play facilities for children) were also compared, and each one showed a statistically significant increase in satisfaction in the new premises.

Comparisons could be made between six individual doctors' rooms in the old and new buildings; those achieving highest satisfaction scores had the most domestic feel, incorporating informal seating (such as armchairs or a sofa), plants, 
decorative objects, and art works, and were also the largest consulting rooms.

Patients' rating of doctor-patient communication also increased in the new premises (Table 2). This score was compared for patients seeing doctors who were present in both premises. Nine doctors worked in the old premises and 11 in the new, but only six took part in both settings. Limiting the comparison to these six doctors meant that any differences in scores were not due to patients seeing different doctors in the two settings.

Free-text comments confirmed that most patients were more satisfied with the reception area in the new building, judging it to be more patient friendly, less noisy and offering greater privacy than in the old surgery:

'Space, light, ambience - general feeling of calm. Artwork and background sound add to this. Reception appears to be less hurried - no phones! - Choice of more privacy good.' (Female, aged 66 years)

In the phase 2 questionnaires, $88 \%$ of patients expressed a preference for the new surgery environment. In response to an open question asking them to explain their preference, the five design features mentioned most often in free-text comments were the greater space, increased light, cleaner and tidier surroundings, more modern appearance, and the art works (including a large aquarium). Patients' comments suggested that improvements to the built environment and interior décor in the new surgery created a more professional appearance, which in turn increased their confidence in the service provided by surgery staff:

'The new waiting area is more spacious, with soft relaxing music playing in the background. The aquarium is fantastic as it puts the patient at ease.' (Male, aged 38 years)

\section{Patient interviews}

Twelve participants were interviewed during phase 1; only six were re-interviewed during phase 2 as the others left the practice, died, or did not book a GP appointment during the phase 2 study period.

In phase 1, numerous patients commented that the design of the reception area provided little privacy during their face-to-face contact with receptionists. Several mentioned that the waiting areas were sometimes cramped, hot, stuffy, noisy (especially if children were present), and that the chairs were uncomfortable if they had to wait a long time.

In phase 2 the majority of patients interviewed preferred the new reception and waiting areas:

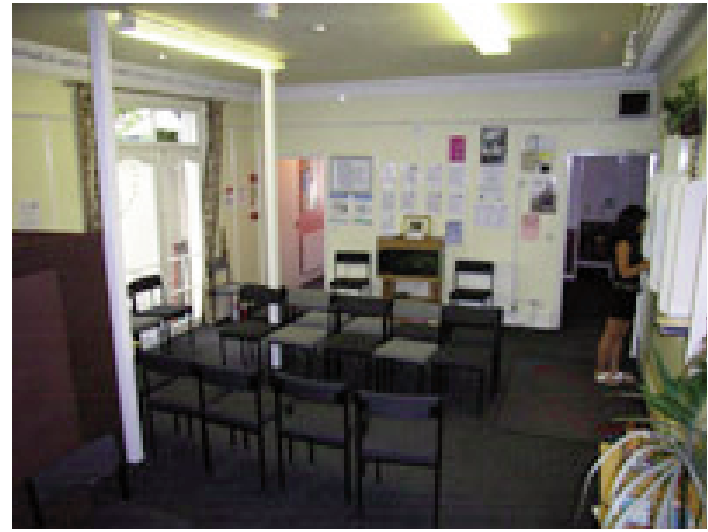

Picture 2. Reception and waiting area, old surgery.

'Because everybody (receptionists in old surgery) seemed to be behind glass and it's more personal where they are now. They have a desk and no glass.' (Female, aged 35 years)

'Very pleasant and professional. It is well put together. The temperature's a lot better then the previous building. That used to be like a sauna.' (Male, aged 53 years)

Picture 3.

Reception area, new surgery.

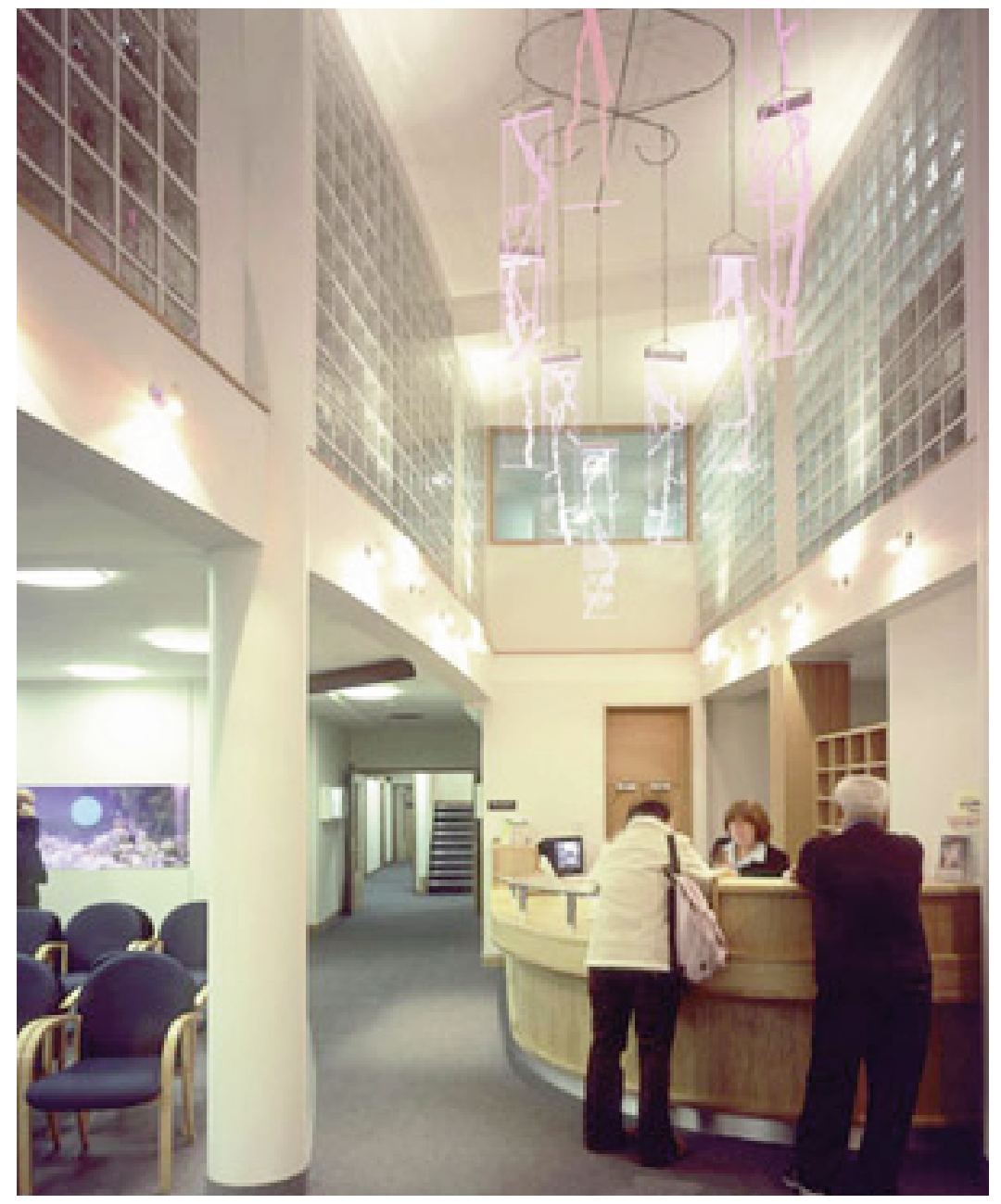




\begin{tabular}{|c|c|c|c|c|}
\hline Score & 1 & 2 & 3 & $\begin{array}{c}\text { ANOVA between } \\
\text { groups over time, } \\
P \text {-value }\end{array}$ \\
\hline Work satisfaction score & 31.37 & 47.84 & 43.68 & $<0.001$ \\
\hline $\begin{array}{l}\text { Work satisfaction for administration/ } \\
\text { reception staff }(n=13)\end{array}$ & 30.54 & 45.08 & 39.92 & $0.002^{\mathrm{a}}$ \\
\hline $\begin{array}{l}\text { Work satisfaction for health } \\
\text { professionals }(n=6)\end{array}$ & 33.17 & 53.83 & 51.83 & \\
\hline GHQ (range 0-12) & 2.21 & 2.47 & 2.74 & 0.66 \\
\hline
\end{tabular}

${ }^{a}$ Administration to health professional comparison. $1=2$ months before the move. $2=4$ months after the move. $3=11$ months after the move. GHQ - general health questionnaire.

When asked to recollect the appearance or atmosphere of consulting rooms in the old surgery, patients' comments included: 'a bit antiquated', 'formal', 'drab', and 'not very comforting'.

In contrast, they described rooms in the new surgery as: 'relaxing and comfortable', 'nice and bright', 'quiet', 'a reasonable size', 'really calm', and 'very professional'.

\section{Staff questionnaires}

Staff questionnaires and focus groups were completed 2 months before the move (September 2005, questionnaire 1), and 4 months (March 2006, questionnaire 2) and 11 months (October 2006, questionnaire 3) after the move. Staff levels changed throughout the study; 27 staff completed questionnaires before the move, and 24 and 23 after the move. Only 19 staff were present at all three time points, and data for these staff are compared over time. They comprised 13 new premises $(4$ month and 11 months after).

Figure 1. Mean staff workplace satisfaction scores from before and after the move to the administrative/reception staff and six health professionals; 15 females, and 4 males.

A workplace satisfaction score for each individual was calculated from responses to 12 questions about their own work area. Table 3 shows that workplace satisfaction increased markedly after moving to the new premises, then decreased a little 7 months later. However, despite the decrease scores remained considerably higher than before the move.

Scores for the administrative/reception staff and the health professionals are shown in Figure 1; statistical comparisons showed that there was a significant difference in the change in scores for the two groups. Health professionals showed the greatest increase in satisfaction levels, which stayed at a higher level. They were much happier with working conditions in the new premises, especially having their own room which gave them greater control over their immediate work environment, as confirmed by free-text comments. Administration and reception staff worked in a different way in the new premises, sharing workspace in a busy openplan office and smaller office upstairs. This way of working was not easy for some, and affected how satisfied they were with the new premises.

GHQ-12 scores were calculated for all staff, and no significant differences were seen at the different time points (lower GHQ scores indicate better psychological health than higher scores). These scores were likely to be more influenced by personal life events, which may have overwhelmed any effects of the working environment.

\section{Staff focus groups}

Views expressed in the focus groups largely echoed those made by individuals in free-text comments on questionnaires. Before the move, many staff voiced their frustration over the lack of storage space, particularly to keep equipment where it was needed, and reported feeling short tempered due to staffroom noise that was very distracting. Staff disliked 'hot desking' which was necessary due to lack of rooms; this prevented staff from completing paperwork in peace. Poor ventilation and lighting made several staff feel very tired at the end of the day, and these environmental problems made their job harder to do.

When asked about the influence of the work environment on overall job satisfaction, many commented that the messiness caused frustration and looked unprofessional, as did the frequent interruptions to find equipment in other rooms. Effects on patients were also mentioned as important, such as a lack of confidentiality and privacy, particularly at the reception desk, and an impression that they were not able to give the best care: 
'I feel my job is all about caring for patients, and providing a decent environment for them at the surgery is my responsibility. I feel ashamed of some aspects of our current surgery environment and this reduces my ability to feel proud of the service I offer to patients.' (Female GP)

After moving to the new premises, staff commented on how the environment positively influenced their mood and wellbeing. Over half of them mentioned that they felt more relaxed, less stressed, or had improved mood:

'Easier to perform well/communicate. More relaxing.' (Male GP)

'My new consulting room is spacious, light, pleasantly decorated and looks attractive and non-clinical. This helps me to feel more relaxed and enhances my mood.' (Female GP)

Others felt that they were doing a more professional job as they were able to provide an improved service for the patients:

'The job feels more professional than it used to and therefore more satisfying.' (Female administration staff member)

'Able to see patients in a quiet private area with no distractions, able to move freely, find things easily, clean area adequately.' (Female practice nurse)

However, after the move there was a rise in the number of patients registering with the practice. This increased workload was mentioned by one or two responders, who felt their job was still stressful and that they had not had time to sort everything out, even several months after the move.

\section{DISCUSSION}

\section{Summary of main findings}

This is the first large-scale study to examine the effects of a UK primary care environment on patients and staff. It suggests that an enhanced environment is associated with improvement in patients' perception of patient-doctor communication, a reduction in anxiety both before and after consultations with a GP, and increases in patient and staff satisfaction. It also identifies design features that contributed to patients' preference for the new primary care facilities compared with the old surgery environment.

\section{Strengths and limitations of the study}

Strengths include the large number of patients sampled. In this study, anxiety ratings were based on

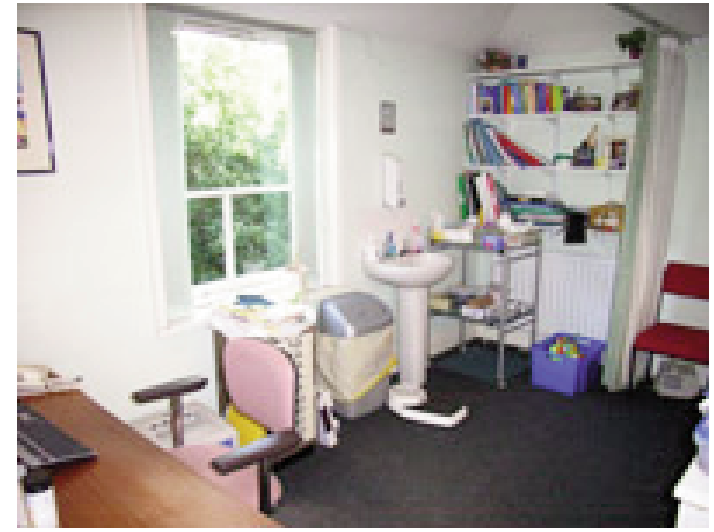

Picture 4.

Consulting room, old surgery.

the validated 6-item short-form of the STAI, whereas Becker and Jones-Douglas's questionnaire included only a single question about patients' anxiety. ${ }^{8}$ When assessing staff response to the new building, the initial 'honeymoon period' was anticipated by including assessments at 4 and 11 months postmove, and the findings showed that increased levels of staff satisfaction with the new environment were maintained.

Staff changes meant that only six GPs consulted with patients in both the old and new premises. The relatively small number of staff members at the study practice also limited the ability to draw meaningful conclusions about the effect of the work environment on their psychological wellbeing from the GHQ.

The study findings are limited in terms of their generalisability, given that they involved a single general practice in a specific locale, and the disparity between the old and new premises may be more dramatic than might be seen with other surgery relocations.

Picture 5.

Consulting room, new surgery.

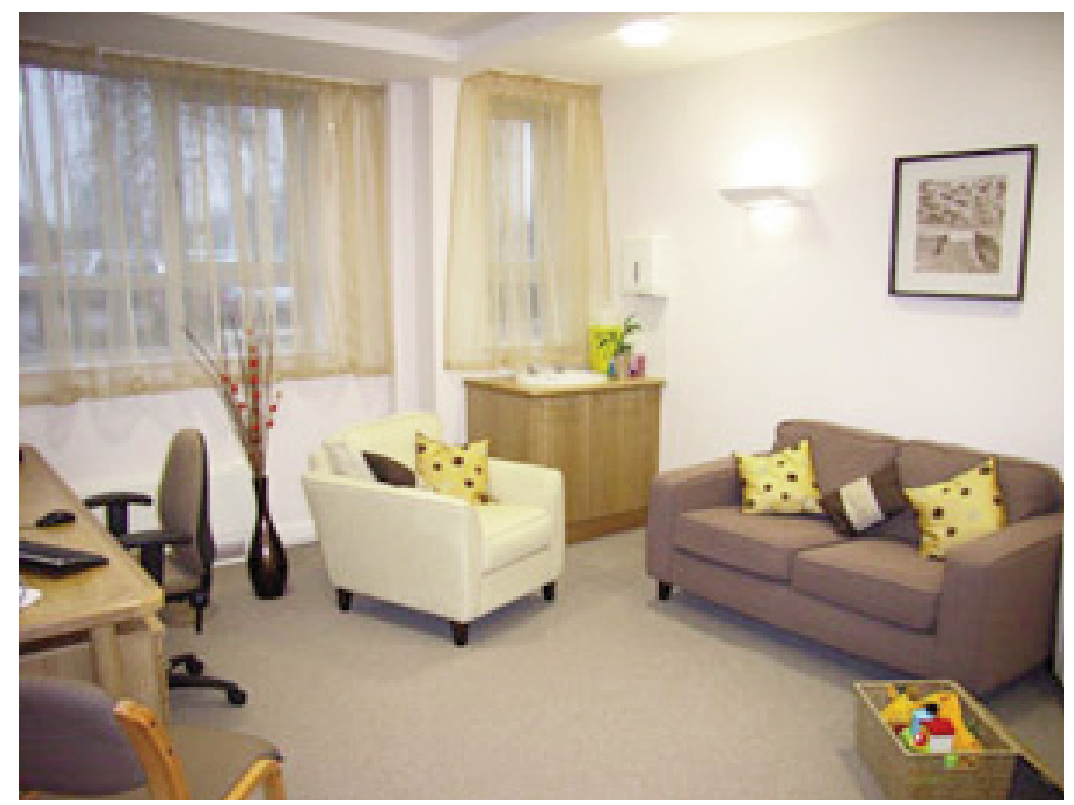




\section{Comparison with existing literature}

This study supports findings from previous research in hospital settings; the built environment of healthcare facilities can have important effects on patients and staff.

Previous studies have found that patients treated in more attractive settings gave higher ratings to their treatment and the staff who delivered it compared with patients in older or more 'typical' settings. ${ }^{3,9,10}$ Controlled experiments in environmental psychology have shown a similar 'appealing setting effect'. ${ }^{11-13}$ The present results suggest that the architectural environment in primary care creates important first impressions for patients: an environment that creates an impression of calm, cleanliness, tidiness and comfort, with features that help to alleviate anxiety, encourages patients to have confidence in the professionalism of the practice and to be satisfied with the care they receive.

Existing research also suggests that the design of the consulting room can facilitate good communication during counselling sessions. ${ }^{14}$ In the present study, patients were most satisfied with spacious consulting rooms that appeared homely rather than clinical. This type of environment may help patients to feel relaxed and able to communicate effectively during the consultation. As several doctors claimed to feel more relaxed in the new surgery, this may have helped them communicate well during consultations. It is also possible that patients' higher rating of doctor-patient communication in the new premises may have reflected their more positive impression of the enhanced surgery environment.

There is support for the role of art in healthcare facilities, for example, contemplation of an aquarium before dental surgery has been found to reduce patient anxiety during treatment. ${ }^{15}$ The large aquarium (one of the commissioned art works in the new surgery) may therefore have helped to reduce some patients' anxiety in this study. Previous studies have shown that emotionally-appropriate art and viewing nature can improve patient outcomes, but inappropriate arts styles, including abstract art, may be detrimental. ${ }^{16-19}$ Art in primary care buildings must therefore be chosen carefully and with an awareness of available scientific evidence in the arts and health field..$^{16,20}$

Existing literature suggests that poorly designed healthcare buildings increase stress among staff, reduce efficiency, and impair job satisfaction, but previous studies have focused on hospital workers. ${ }^{1,21}$ This study shows that the physical environment is also important to primary care staff. The design of the new premises meant that doctors and nurses had almost exclusive use of their own rooms and so were able to individualise and control their personal workspace much more than nonclinical staff. Vischer has highlighted the impact of personalised space and territory on performance and efficiency in the corporate sector and industry; ${ }^{22}$ it would seem the same holds true for primary care. Having unfettered access to their own working space meant health professionals felt able to work more effectively. The findings of the present study should be borne in mind when judging the apparent costeffectiveness of room space use in primary care buildings.

\section{Implications for future research and clinical practice}

By identifying key elements of the primary care environment that produce benefits for staff and patients, it is hoped that this study's findings will prove useful to healthcare facility designers, planners, primary care trust and practice managers, GPs, and other clinical staff. Better buildings will help improve the patient experience and support primary care staff in their endeavours to provide the best health care possible for patients.

\section{Funding body}

Funding for the project, which was part of the wider 'Pathfinder' research programme looking at enhancing the healing environment, was provided by the (then) NHS Estates Agency. Since the abolition of that agency in 2005, the Pathfinder programme has been managed by the Estates and Facilities Division of the Department of Health, Room 3N09, Quarry House, Quarry Hill, Leeds LS2 7UE. The authors' work was independent of the funders

\section{Ethical approval}

Southmead Research Ethics Committee, Bristol (05/Q2002/23)

\section{Competing interests}

The authors have stated that there are none

\section{Acknowledgements}

We thank the patients and staff at Bedminster Family Practice, Bristol for their participation in this study, and all members of the project steering group for their helpful advice and support. We also thank Zoe Lowrie for her work as research assistant and Rosemary Greenwood for statistical analysis.

\section{Discuss this article}

Contribute and read comments about this article on the Discussion Forum: http://www.rcgp.org.uk/bjgp-discuss.

\section{REFERENCES}

1. Ulrich R, Zimring C. The role of the physical environment in the hospital of the 21st century: a once-in-a-lifetime opportunity. http://www.healthdesign.org/research/reports/physical_environ.php (accessed 2 Apr 2008)

2. Mizan J, Ballard K. A qualitative study exploring the effect of the built environment on doctor-patient interaction in primary care. http://www.the-space-works.org/ (accessed 2 Apr 2008).

3. Ingham B, Spencer C. Do comfortable chairs and soft lighting in the waiting area really help reduce anxiety and improve the practice's image? Health Psychol Update 1997; 28: 17-20.

4. Kantrowitz M. Plenary session: design evaluation of six primary care facilities for the purpose of informing future design decisions. $J$ Healthc Des 1994; 6: 19-25.

5. Marteau TM, Bekker H. The development of a six-item short form of the state scale of the Spielberger state-trait anxiety inventory 
(STAI). Br J Clin Psychol 1992; 31(Pt 3): 301-306.

6. Mulholland B, Marks M, Lightman SL. Anterior uveitis and its relation to stress. Br J Ophthalmol 2000; 84(10): 1121-1124.

7. Golderberg D, Williams P. A user's guide to the General Healt questionnaire. Windsor: NFER-Nelson, 1988.

8 Becker F, Jones-Douglas S. The ecology of the patient visit: attractiveness, waiting times, and perceived quality of care. Healthcare Design 2006; 6(7): 12-19.

9. Lawson B, Phiri, M. The architectural healthcare environment and it effects on patient health outcomes. London: The Stationery Office, 2003.

10. Swan J, Richardson L, Hutton, J. Do appealing hospital rooms increase patient evaluations of physicians, nurses and hospital services? Health Care Manage Rev 2003; 28(3): 254-264.

11. Maslow AH, Mintz NL. Effects of aesthetic surroundings; initial effects of three aesthetic conditions upon perceiving 'energy' and 'well-being' in faces. J Psychol 1956; 41: 247-254.

12. Biggers T, Pryor B. Attitude change: a function of emotion-eliciting qualities of environment. Pers Soc Psychol Bull 1982; 8(1): 94-99.

13. Arneill AB, Devlin AS. Perceived quality of care: the influence of the waiting room environment. J Environ Psychol 2002; 22(4): 345-360.

14. Chaikin AL, Derlega VJ, Miller SJ. Effects of room environment on self-disclosure in a counseling analogue. J Couns Psychol 1976; 23(5): 479-481.

15. Katcher A, Segal H, Beck A. Comparison of contemplation and hypnosis for the reduction of anxiety and discomfort during denta surgery. Am J Clin Hypn 1984; 27(1): 14-21.

16. Ulrich R, Gilpin L. Healing arts: nutrition for the soul. In: Frampton SB, Gilpin L, Charmel P (eds). Putting patients first: designing and practicing patient centred care. San Francisco, CA: Jossey-Bass, 2003; 117-168.

17. Carpman JR, Grant MA. Design that cares: planning health facilitie for patients and visitors. 2nd edn. Chicago, IL: American Hospital Publishing, 1993

18. Ulrich RS, Lunden O, Eltinge JL. Effects of exposure to nature and abstract pictures on patients recovering from heart surgery [abstract]. Presented at the 33rd Meeting of the Society for Psychophysiological Research, 1993, Rottach-Egern, Germany. Psychophysiology 1993; 30(suppl 1): 7.

19. Ulrich RS. Effects of gardens on health outcomes: theory and research. In: Marcus CC, Barnes M (eds). Healing gardens: therapeutic benefits and design recommendations. New York, NY: John Wiley, 1999; 27-86.

20. Staricoff R. Arts in health: a review of the medical literature. London: Arts Council England, 2004

21. Joseph A. The role of the physical and social environment in promoting health, safety and effectiveness in the healthcare workplace. http://www.healthdesign.org/research/reports/workplace.php (accessed 1 Apr 2008).

22. Vischer JC. Space meets status: designing workplace performance. Oxford: Routledge, 2005. 